\title{
Planning an Environmental Education Project for Kindergarten under the Theme of "the Forest"
}

\author{
Christos A. Tsekos (Corresponding author) \\ Department of Environmental and Natural Resources Management \\ University of Western Greece \\ 30100, G. Seferi 2, Agrinio, Greece \\ E-mail: ctsekos@yahoo.gr \\ Elena I. Christoforidou \\ Department of Early Childhood Care and Education \\ Technological Educational Institute of Epirus \\ 30100, Ioannina, Greece \\ E-mail: ctsekos@yahoo.gr \\ Evangelos A. Tsekos \\ Department of Primary Education \\ University of Ioannina \\ 45110, Ioannina, Greece \\ E-mail: e.tsekos@yahoo.com
}

Received: February 23

Accepted: March 27, 2012 Published: June 1, 2012

doi:10.5539/res.v4n2p111

URL: http://dx.doi.org/10.5539/res.v4n2p111

\begin{abstract}
The primary aim of the Environmental Education since its initial appearance and throughout the previous decades has been the formation of ecological awareness from early ages. So far, most of the International Conferences have been highlighting the fact that Environmental Education should be introduced since preschool age. The Project Method constitutes a much different educational approach in comparison with the traditional educational methods, which have been implemented throughout the previous years. It is mainly characterized by its student-centered nature, the more active role attributed to the person undergoing education and, among others, the mutual collaboration between the children and the educator so as for the desired outcome to be achieved. The aim of this article is to propose a project for pupils of preschool age under the theme of "The Forest". All its successive stages (from the introductory to the presentation-announcement stage) are analyzed by means of activities appropriate for children of preschool age and therefore, can easily and readily be realized by them.
\end{abstract}

Keywords: Environmental education, Project method, Forest, Kindergarten

\section{Introduction}

As it is commonly accepted, Environmental Education was officially established in the 70's by the significant International Conferences held in Nevada (1970), Stockholm (1972), Belgrade (1975) and Tbilisi (1977). These Conferences laid the foundations and defined the objectives, the targets and the methodology framing Environmental Education on an international level (Palmer, 1998 and Dimitriou, 2009). The First Intergovernmental Conference on Environmental Education, which took place in Tbilisi in 1977, explicitly states that its implementation should be commencing from preschool age and continuing throughout the school years, let alone extending to an out-of-school level (Palmer, 1998). 
Environmental Education is not a one-dimensional procedure as is the case of traditional education in which the educational asset is offered only by means of the "frontal" teaching. On the contrary, it possesses a three-dimensional character as it is internationally accepted (Palmer, 1998).

More specifically, Environmental Education is divided into three forms:

a. Environmental Education about the environment

b. Environmental Education in or from the environment

c. Environmental Education for the environment

This distinction is consistent both with the psychological data and more specifically the correspondence with the cognitive, emotional and ethical aspect of human personality and the pedagogical data since it accords with Bloom's tripartite taxonomy of the educational objectives into a cognitive, emotional and psychokinetic area (Skanavis, 2004). The first form of Environmental Education (which correlates with the cognitive hypostasis of the personality) attempts to transfer knowledge through teaching subjects which refer to the Environment on scientific fields related not only to Natural Sciences, e.g. Physics, Chemistry, Biology, Geology, but also to Social Sciences and Humanities, e.g. Economics and History. Additionally, the last one is based on the principle that environment is composed by the natural and the anthropogenic environment (Tsekos and Matthopoulos, 2009). The second form of Environmental Education appears through activities realized in the environment as such, where the participants can experience it, its value and its problems directly and personally by assuming activities within it. Last but not least, the third form is about our moral attitude towards the environment and it deals with shaping ecological values, attitudes and behaviors.

The interdisciplinary approach of knowledge is in action in the Greek Kindergarten system, and educational method that renders the implementation of "Projects" possible. The Integrated Thematic Curriculum addressed for Kindergarten consists of the following five cognitive subjects, which are not considered as discernible: a) Child and Language, b) Child and Mathematics, c) Child and Environment, d) Child and Creativity - Representation (Artistic Expression etc) and e) Child and Informatics. More specifically, the Planning and Development Program in the activities of Environmental Education incorporates as study subject everything that surrounds us, i.e. human beings and their fabrications, social relations, animals, plants, places natural phenomena and situations. Environmental Education is addressed to Natural Environment (including Science), as well as to the Anthropogenic Environment related to human activity (Michalopoulou and Chiotaki, 2008).

Project Method inarguably constitutes a different approach to education compared to the traditional methods. As a method, it was first applied at the beginning of the 20th Century (Doliopoulou, 2006) and its fundamental principals can be traced to the ideas and the work of educators like Dewey, Kilpatrick, Decroly and Piaget (Katz and Chard, 1995; Grollios, 2005).To some extent, it is virtually considered to be the offspring of the American Progressive Movement in Education (Knoll, 1997, Dimitriou, 2009). Moreover, it appears that the Project Method consists in certain elemental features which distinguish it from the traditional teacher-centered approaches in education. These important features are the following: a) any independent and self-determined activity is reinforced and the students are encouraged to undertake initiatives and act deftly, b) mutual co-operation is promoted among students (in contrast to other traditional methods), c) creative thinking is cultivated, and d) the teachable material is linked to everyday life (Frey, 2002). In general terms, in the Project Method the action as a whole is determined by all the participant members, a prerequisite which fully justifies its "flexible" nature. In practice, that means there is not a unique schedule to be followed in any project and that the objective, on which the participants focus, can be formulated as the project unfolds depending on the interests and the capabilities of the children. Furthermore, a crucial particularity of this method is the fact that the educator plays a more guiding and consultative (compared to the traditional frontal teaching) rather than purely didactic role. Rogoff, additionally, describes the process of learning through the help of adults as a "guided participation" so as to place special emphasis upon the cooperation of the children with the other participants so that they can proceed to more sophisticated knowledge and skills levels (Rogoff, 1990). The fact that through that method both the social interactions and the cooperativeness among children are promoted is considered to be particularly important; especially if one considers that the children's social interactions help them in the learning process (Poimenidou and Christidou, 2011) and in developing their self-confidence as well as other social skills (Bredekamp and Copple, 1997). On the other hand, according to Bredekamp and Copple, children who fail to develop a rudimentary sociability and are neglected or rejected by their peers are likely discontinue school and may be subjected to psychological problems as adults (Bredekamp and Copple, 1997).

Regarding the potentials and the significance of this method it suffices to consider the following: a) surveys conducted by the American psychologist J.Bruner have shown that people manage to retain only $10 \%$ of what they 
hear, $30 \%$ of what they read, $50 \%$ of what they see and $90 \%$ of what they do (Lemke and Baehr, 2011) and b) according to contemporary pedagogic surveys the educational curricula which manage to fulfill their objectives to a greater extent are those which succeed in getting the parents to participate in the learning process (Dodge and Colker, 1998).

On the whole, the principal objective of the present article is a dual one; firstly, to suggest a Project appropriate for children of preschool age under the theme "The Forest" and secondly, to present analytically all the successive stages which comprise it.

\section{Forest Ecosystems}

One of the most important reasons why the forest ecosystems were selected as the object of this project is their significance to mankind. As Miller states, since the forests constitute a shelter for approximately $50-60 \%$ of all the species on our planet and especially for wildlife species, if we continue to exploit them under the current circumstances, they will be on the verge of extinction in the following 30-50 years (especially the rainforests) (Miller, 1996). It is an undeniable fact that forest land contributes to averting the intense superficial water runoff and the subsequent floods, as well as to the provision of shelter and food for wildlife (Cunningham and Saigo, 1998). Additionally, woodland is conducive to climate adjustment and the avoidance of extreme temperatures in a region due to the shadow offered by trees and the evaporation of the water from their leaves (Enger and Smith, 1995). Especially nowadays the forests can resolutely conduce to abate the greenhouse effect, since they dispose great potentials in absorbing the carbon dioxide the emission of which is primarily to be held responsible for this phenomenon. As it is also known, forests are not only exploited on account of their timber, which provides combustible material, but also for other purposes such as for the development of agricultural activities in a former forest area. The deforestation of the rainforests in Latin America, Africa and Asia at a rate of $1 \%, 0.8 \%$ and $1.2 \%$ per year respectively, is indicative of the grave problem created by the intense exploitation of the forest resources (Enger and Smith, 1995).

\section{Activity Planning}

In general, the Project Method is divided into six stages (Katz and Chard, 1995; Doliopoulou, 2006).

a) Introduce the theme

b) Exchange of knowledge and ideas between the children and the educator

c) Record the children's ideas on a histogram

d) Activity implementation stage

e) Briefing and feedback intervals

f) Completion stage

To proceed, what each stage individually includes will be thoroughly examined.

a) Introduce the theme of the Project

The educator attempts to draw the children's interest through means of opening a conversation, projecting slides, organizing a field trip or listening to infant's query. The purpose of this stage is basically to smoothly introduce the children to the particular theme.

In order for the educator to further stimulate the children's interest as well as to prepare them for the forthcoming field trip to the forest, the following magic fairytale could be narrated.

\section{"The Fairy of the Forest"}

Little Helen, cautiously moving on the tiptoes so as not to waken her grandmother who had already fallen asleep in the living room by the fireplace, opened the door gently and rushed outside the house and into the yard. It was late in the afternoon and the sun was setting transforming itself into a scarlet sphere painting red, as if smeared in blood, the clouds which were resting on the crest of the facing mountain like a wreath. Little Helen was on the look-out for some flowers in the garden. After all, she had promised her teacher she would get her some for the school fair taking place the following day. She was so absorbed, however, into doing her homework that she forgot to visit the forest opposite her house to pick some flowers, so she was now in a hurry to fulfill her promise before the night would arrive. At first, she cut some gerberas and then some brown chrysanthemums from her grandma's garden. Soon enough she was in the forest. She crossed the bridge that joined the banks of the rivulet which was streaming its crystal clear waters at the edge of the forest and she vanished into the towering trees. How beautiful everything was! Enormous plane trees were flashing reddish sunlight sheening their leaves, verdurous firs whose twigs looked like half-opened wings of big birds, old pine trees heeling their trunk as if they were weary as well as 
other trees whose names Little Helen was not aware of. The birds were singing the last song before they fell asleep and Little Helen realized that the forest offers many more besides its beauty as her teacher had so accurately explained the previous day. As she was walking in the woods, she suddenly heard steps behind her. She immediately stopped! Frightened though she was she turned around and saw a tall young woman approaching her. Little Helen could not help but notice how exceptionally beautiful she was. She had long blonde hair and green eyes while her face was concealed under a white, yet transparent, veil illuminating a golden light. Her hands were full of flowers: purple and pink roses were forming a pretty and fragrant bunch of flowers which smelt sweet while two elegant wings were protruding from its back. Little Helen looked at her in awe, but in fear too.

"Please, do not be afraid Little Helen", said the woman. "My name is Stella and I am forest fairy. I am the keeper of this forest. Those who come here during the night are usually of no good intentions. Those I chose to punish by taking their voice so as not to be able to speak anymore. You, on the other hand, have nothing to fear of! You see, I already know that you have come here just to gather some fragrant blooms. That's why I brought some for you so as to give them to your teacher".

The fairy generously lent her hand and offered the flowers to Little Helen who was so scared that she forgot to thank the fairy for this gentle gesture.

"A Fairy!" Little Helen thought. "What if she's lying to me? What if she's simply trying to fool me and take me with her?"

"Please, do not be afraid", said Stella who had already read Little Helen's suspicious mind. "I am going to take you back to your grandmother now. You know, she's been looking for you."

The fairy gently cuddled Little Helen and then swiftly arose up in the sky flying towards the edge of the woods where they saw Little Helen's grandmother calling for her. Stella went down, left Little Helen on the ground behind a tree and vanished in a white mist full of colorful little stars.

"You should always love the forest!" said the fairy from high up above.

"Stella!! Thank you for the flowers" said Little Helen and went on to meet her grandmother as the forest was overwhelmed in the silver light shed by the yellow sphere-like moon suspending from the sky.

It is recommended that the fairytale be sided with relevant visual material such as a poster $(1.5 \times 2.5 \mathrm{~m})$ which will be tagged on the wall and in front of which the children are to be gathered to listen to the narration. Picture 1 presents ancillary teaching material for the fairytale (the Fairy is holding Little Helen by the hand).

b) Exchange of knowledge and ideas between the children and the educator

The children and the educator exchange knowledge through different ways such as drawing, conversing, projecting photos etc. At this stage the educators ought to encourage, if possible, all the children to voice any relevant knowledge, ideas as well as any experiences they possess so that they can perceive, right from this initial stage of the Project, that their participation is equal and that the ideas and the opinions of everyone will definitely be heard.

c) Record the children's ideas on a histogram

This stage includes recording of the pupils' ideas (those related to the theme) onto small cards which the educator is to utilize for creating a histogram. Therefore, at this stage, the educator limits the width and the vagueness of the theme (e.g. from the environment in general towards the forest in particular) and forms specific subunits regarding it. The children are then divided into groups and after they have expressed their queries and their ideas they decide jointly with their educator, on the way they will work on their Project. Nevertheless, the educator holds the final responsibility concerning the selection of the theme once she has taken into consideration the time on hand, the available materials and the potential response of the children on the proposed theme.

d) Activity implementation stage

This is the most time consuming stage as it includes various activities to be realized by the children. In this particular project we believe that in order for it to be materialized in the best possible way, the activities should be actualized both inside and outside the kindergarten. Therefore, initially a walk-field trip should be organized so that the children can collect items, get information via observation and virtually "meet" directly the forest ecosystem. Later on, the pupils' and the educator's activities are to be transferred into the Kindergarten.

During the visit in the forest certain teaching aids and materials such as cameras, magnifying glasses, sound recorders as well as computers for the projection of the images will be needed with a view to assisting in the organization of the activities in the best possible way. Picture 2 presents a food web in a forest ecosystem. 
Thus, after the visit to a forest and before the initiation of the activities, the educator should have a small conversation with the pupils concerning the forest and explain that (Picture 2 can be of assistance while interpreting the following points):

- The plants remain firmly rooted in a place, whereas the animals and the birds move

- Some plants are short (bushes, turfs) whereas others are tall (trees)

- The trees are initially small, yet they grow as time lapses

- Some animals eat plants while others feed on other animals to survive

- We should not harm or cause the death of any living organism without any reason

- We must protect the forests since they are invaluable to humankind as they provide us with oxygen and since they "house" many organisms.

Then the children along with the educator commence the activities. The educator encourages the pupils to participate with all their senses, since Environmental Education targets the cognitive, the emotional and the ethical involvement of the educatee with the issue under study (Palmer and Neal, 1994). Therefore, Environmental Education focuses on encouraging the children to actually feel the flowers and the tree trunks, smell any characteristic scents of the forest (like that of the resin) and hear the leaves swishing, but simultaneously should be particularly attentive so that no child gets hurt from any piece of glass or any other sharp objects to be found in the location of the visit.

After the children are divided into different groups, they are assisted by their educator to capture images of characteristic parts of the forest. For example cypresses, firs, stones, bushes, birds and flowers. It is worth mentioning that since many animals, trees and plants of the forest are rare and cannot be found easily and quickly in any forest (e.g deer, tortoises, squirrels, snakes, cypresses, firs) the educator could project a series of pictures on the computer and ask the pupils to identify the objects projected and mention some of their distinct characteristics (e.g. the fact that the tortoise hides into its shell or that the snake is poisonous and therefore dangerous). Picture 3 shows a picture to help children realize the difference between the evolutions of the animate organisms and the inanimate objects.

Another activity that could be actualized into groups in the form of play is to assign the children with the task to collect as many different items as possible (e.g. leaves, twigs, stones, flowers, pinecones etc). The team that collects the most different items will be the winner. Especially as far as the importance of playing at preschool age is concerned, Wood mentions there is nowadays ample data to prove that through playing children not only exhibit improved verbal, social and communication skills as well as creative use of educational material but also develop problem solving skills (Wood, 2007).

Later on, the educator can divide the children into teams which will be engaged into drawing activities. Based on the memories and the impressions of the children the educator can develop their perceptiveness by employing a herbarium with drain leaves. Children will then be asked to draw the contours of the leaves, their colors, their place onto the twigs or, what is more difficult, to draw the distinctive outline of some kinds of trees (e.g. the fir).

To continue, another activity would be to project drawings depicting the evolution of the vegetative and animal organisms. That will enable children to understand on the one hand the importance of the evolution of the living beings and on the other hand grasp the difference between the living beings and the inanimate objects. One example is Picture 3, which portrays the evolution of a rose and a hare in contrast with the non-evolution of a stone, which naturally does not evolve or develop with the passage of time.

Upon their return to the kindergarten the children are encouraged to express their own ideas, their feelings and their experiences which were acquired during that visit. According to Fisher, encouraging the children to express their feelings is of supreme importance, since when they express orally what they have seen and learned, as well as the way in which they have conquered that knowledge, then their thoughts and their speech provide the educator with sufficient data that will help her/him "build" the next steps to the educational procedure (Fisher, 1998).

The group activities which were initiated in the forest are not to be terminated at that point but to be continued in the kindergarten too. We believe that the successive activities could actually contribute to the parallel boost of social, language, emotional, cognitive and kinetic skills, which are necessary to be developed to children of preschool age (Bruce, 2005; Chatzisavvidis, 1998). Therefore, children:

- Can learn how to count by means of practical examples such as how many legs and wings an insect has or how many eyes there are on an animal 
- Will be engaged in grouping-classification (e.g. animals-plants and animate-inanimate) and matching (trees-corresponding fruits) activities

- $\quad$ They sing "The Colorful Forest" (Charalambous, 2000)

e) Briefing and feedback intervals

Throughout the implementation stage of the Project, intervals for briefing and feedback among the groups are to take place, during which children can exchange ideas, solutions and experiences and the educator may record the progress of the whole procedure.

\section{f) Completion stage}

At this stage, the educator along with the children determines the termination of the activities. Later on, the presentation-announcement of the results of the project is to follow. This stage is one of the most elemental parts of the Project Method since the children are not simply required to recall everything they have acquired during the implementation phase of the particular project but also to represent it symbolically. At this stage therefore, the children share with the community in which they live, with the children of other classes and with their parents whatever they have "experienced" in this particular project in a symbolic way such as a puppet show, a theatrical play, a conversation, a maquette construction etc. Even though it is our belief that the most important part of this method is the learning "path/route" that is followed and not the final tangible outcome, we think that it would be much preferable for the project to result in the formation of a tactile product by the children (e.g. a maquette, a poster) so that they can have the sensation that there is a specific objective in their assignment and to be able to watch it being transformed into a tangible outcome which they can share with others. Last but not least, what is of supreme importance in this stage is the participation of the parents who on the one hand should show that they are interested in the Lilliputian pupils' creations and on the other hand encourage them to attempt other projects in the future.

\section{Conclusions}

The theoretical foundation of Environmental Education stands on the progressive pedagogic movement of "New Education" and the alternative pupil-centered methods introduced by Dewey and Kilpatrick. Environmental Education enhances pupil-centered Education, while utilizes children's pre-existing knowledge and experiences in order to build up new knowledge, and enhances the conjunction of knowledge with their interests and their every-day life (Georgopoulos, Birbili and Dimitriou, 2011). In parallel, it supports personality's autonomy and the development of critical thinking, as well as values. The major factor responsible for the emergence of environmental issues is the way the decisions regarding the exploitation of the environment and the natural resources are taken by contemporary societies. Thus, the importance of Environmental Education lies on the initiatives taken upon citizens on issues of interest.

Taking the aforementioned into consideration it can easily be understood that not only does the Project Method promote to a great extent the independent and especially self-determined activity of the children via their undertaking initiatives, acting according to their interests, collaborating with each other/mutually and expressing everything they have learned but also it provides them with useful "experiences" to accompany them throughout their lives. As it was already mentioned in another part of the present article, the Project Method is an alternative way of teaching and in no occasion does it substitute the analytical curriculum as it is impossible for the whole content of the subjects to be taught only through Projects as such. Nevertheless, this way of teaching poses a great opportunity for children to meet the world out-of-school virtually by "experiencing" it directly. To realize how important these experiences are we think it is necessary to mention the fact that according to Bredekamp and Copple the early experiences affect the development of a child cumulatively and in a long-term (Bredekamp and Copple, 1997). Additionally, there are an increasing number of surveys which show that the social and kinaesthetic experiences during the first years of a child may directly affect the neurological development of the brain with important and long-term consequences in the children's ability to learn (Dana Alliance for Brain initiatives, 1996). To conclude, every project is an original and innovative learning opportunity, a unique chance for every participant to learn but mainly to encounter new experiences, a unique "journey" which each participant ought to try and experience in his/her own way.

\section{References}

Bredekamp, S., \& Copple, C. (1997). Developmentally Appropriate Practice in Early Childhood Programs. Washington: NAEYC Publications.

Bruce, T. (2005). Early Childhood Education. London: Hodder Arnold. 
Charalambous, A. (2000). I play and I sing. Private Publication: Athens.

Chatzisavvidis, S. (2002). Language Education in Kindergarten. Thessaloniki: Vanias.

Cunningham, W. P., \& Saigo, B. W. (1998). Environmental Science: A Global Concern. New York: Mc Graw-Hill.

Dana Alliance for Brain Initiatives. (1996). Delivering results: a progress report on brain research. Washington. Dimitriou, A. (2009). Environmental Education: Environment, Sustainability: Theoretical and pedagogical approaches. Thessaloniki: Epikentro Publications.

Dodge, D. T., \& Colker, L. J. (1998). The creative curriculum for early childhood. Washington: Teacher Strategy Inc.

Doliopoulou, E. (2006). Contemporary Trends in Preschool Education. Athens: Gutenberg.

Enger, E. D., \& Smith, B. F. (1995). Environmental Science: A Study of Interrelationships. New York: Mc GrawHill.

Fisher, J. (1998). Starting from the child? Teaching and learning from 4 to 8. Philadelphia: Open University Press.

Frey, K. (2002). Die Projektmethode. Weinheim: Beltz.

Georgopoulos, A, Birbili, M., \& Dimitriou, A. (2011). Environmental Education and Experiential Education: A Promising Marriage for Greek Pre-School Teachers. Creative Education, 2(2), 114-120. http://dx.doi.org/10.42 36/ce.2011.22016

Grollios, G. (2005). Dimensions of Project Method's History. In Georgopoulos, A. D. (Ed.), Environmental Education: the new Culture which arise (pp. 535-549). Athens: Gutenberg.

Katz, L. \& Chard, S. (1995). Engaging children's minds: the Project approach. New Jersey: Ablex Publishing.

Knoll, M. (1997). The Project method: its Vocational Education origin and international development. Journal of Industrial Teacher Education, 34(3), 59-80.

Lemke, R. A., \& Baehr, M. (2009). AV Megatrends: opportunities and implications. [Online] Available: $\mathrm{http} / / / \mathrm{www}$. infocomm.org/cps/rde/xbcr/infocomm/megatrends.pdf (October 25, 2011).

Michalopoulou, K., \& Chiotaki, E. (2008). Activities for the discovery and the understanding of the Environment from preschoolers. Athens: Kastaniotis.

Miller, G. T. Jr. (1996). Living in the Environment: Principles, Connections and Solutions. Belmont: Wadsworth Publishing.

Palmer, J., \& Neal, P. (1994). The Handbook of Environmental Education. London and New York: Routledge.

Palmer, J. (1998). Environmental Education for the $21^{\text {st }}$ Century. London: Routledge.

Poimenidou, M., \& Christidou, V. (2010). Communication Practices and the Construction of Meaning: Science Activities in the Kindergarrten. Creative Education, 2, 81-92. http://dx.doi.org/10.4236/ce.2010.12013

Rogoff, B. (1990). Apprenticeship in thinking: Cognitive development in social context. New York: Oxford University Press.

Skanavis, K. (2004). Environment and Society. Athens: Kaleidoskopio.

Tsekos, C. A., \& Matthopoulos, D. P. (2009). Ethics, Science and the Environment: the need for a new environmental worldview. International Journal of Environmental Studies, 66(6), 679-687. http://dx.doi.org/10.1 080/00207230903028326

Wood, E. (2007). Developing pedagogy of play. In Anning, A., Cullen, J., \& Fleer, M. (Eds), Early childhood education: society and culture (pp. 19-30). Los Angeles, London, New Delhi, Singapore: Sage Publications. 